\title{
Relações entre o Índice de Basiléia e o Nível de Endividamento das Famílias Brasileiras
}

\author{
Relations between the Basel Index and the Level of Indebtedness of Brazilian Families
}

\author{
Sabrina Espinele da Silva \\ Graduanda em Controladoria e Finanças pela UFMG \\ Bolsista do sistema de bolsas de Controladoria \& Finanças. \\ Av. Pres. Antônio Carlos, 6627 - Pampulha, Belo Horizonte - MG \\ E-mail: sabrinaespinele@gmail.com \\ Bruno Peréz Ferreira \\ Doutor em Administração/Finanças pela UFMG. \\ Prof. Adjunto do CEPEAD/FACE/UFMG. \\ Av. Pres. Antônio Carlos, 6627 - Pampulha, Belo Horizonte - MG \\ E-mail: brunoperez.bh@gmail.com
}

\begin{abstract}
Resumo
O acordo de Basiléia impõe um capital mínimo regulatório para que os bancos mantenham sua liquidez e sejam menos suscetíveis a choques provenientes da interligação do sistema financeiro. Os bancos precisam administrar a dinâmica de captações e das aplicações de modo a evitar o excesso ou escassez de recursos monetários, eles estão expostos a riscos como o risco de crédito e o risco de liquidez. Risco de credito trata-se do risco de que a contraparte na transação não honre sua obrigação. Risco de liquidez trata-se do risco de a instituição financeira tornar-se incapaz de honrar suas obrigações. $O$ índice de endividamento das famílias brasileiras apresentou crescimento no período analisado, e um nível de endividamento elevado aumenta as chances de inadimplência e expõem as instituições financeiras ao risco de crédito e ao risco de liquidez. Assim, o objetivo desse artigo consiste em analisar as relações existentes entre o índice de Basiléia divulgado pelos bancos e o alto nível de endividamento das famílias no Brasil. O estudo utilizou dados disponíveis no sistema gerenciador de séries temporais (SGS) do banco central do Brasil, que compreendem o período de janeiro de 2005 a dezembro de 2013, sendo analisadas as seguintes variáveis: índice de Basiléia, endividamento, inflação IPCA, taxa Selic, Inadimplência no SPC, através de um modelo ARCH (Autoregressive Conditional Heteroskedasticity). Os resultados demonstram que o índice de Basiléia, e o nível de endividamento das famílias possuem correlação negativa, o que faz com que os dois variem em sentidos opostos. Podemos comparar os resultados do modelo para o sistema financeiro brasileiro com o que foi observado no mercado americano, visto, por exemplo, da ótica dos autores que apontam o começo da crise financeira de 2008 , como consequência do alto endividamento das famílias americanas no ramo de hipotecas.
\end{abstract}

Palavras-chave: Índice de Basiléia; Endividamento das famílias; Acordo de Basiléia. 


\begin{abstract}
The Basel Accord imposes a regulatory minimum capital requirement for banks to maintain their liquidity and are less susceptible to shocks from the interconnection of the financial system. Banks need to manage the dynamics of funding and applications in order to avoid excess or shortage of monetary resources, they are exposed to risks such as credit risk and liquidity risk. Credit risk is the risk that the counterparty in the transaction does not honor its obligation. Liquidity risk is the risk of the financial institution become unable to honor its obligations. The debt ratio of Brazilian families grew during the period analyzed, and a high level of debt increases the chances of default and expose financial institutions to credit risk and liquidity risk. The objective of this article is to analyze the relationship between the Basel index released by the banks and the high level of household debt in Brazil. The study used data available at the time series management system (SMS) of the Central Bank of Brazil, which cover the period from January 2005 to December 2013, the following variables: Basel index, debt, inflation IPCA, Selic rate, Delinquency in SPC through an ARCH model (Autoregressive Conditional Heteroskedasticity). The results demonstrate that the Basel index, and the household debt levels have negative correlation, which makes the two vary in opposite directions. We can compare the model results for the Brazilian financial system with what was observed in the US market, as, for example, the perspective of authors who point to the beginning of the financial crisis of 2008, as a result of high indebtedness of American families in the business of mortgages.
\end{abstract}

Key-words: Basel index; household debt; Basel Accord.

\title{
1 Introdução
}

Após a crise financeira mundial ocorrida em 2008, aumentaram-se as preocupações com a inadimplência no sistema bancário, e passaram a ser adotadas medidas de precaução para que os bancos incorram em menos perdas, ocorridas situações adversas de inadimplência. Uma dessas medidas consistiu na reformulação do acordo de Basiléia; acordo que impõe um capital mínimo regulatório para que os bancos mantenham sua liquidez, e visa fazer com que as instituições financeiras sejam menos suscetíveis a choques provenientes do sistema financeiro ou dos demais setores da economia.

De acordo com Santos (2001), uma das principais funções dos bancos na economia consiste na intermediação financeira entre os agentes econômicos superavitários (aplicadores de recursos) e os agentes econômicos deficitários (demandantes de crédito). Entretanto, Diamond e Dybvig (1983) ressaltam que os bancos são também provedores de liquidez. Por consequência, estes precisam administrar a dinâmica das captações e das aplicações de modo a evitar o excesso ou escassez de recursos monetários.

O Comitê de supervisão bancária da Basiléia define liquidez como a capacidade de um banco para financiar aumentos dos ativos e cumprir obrigações sem incorrer em perdas inaceitáveis. A importância da liquidez para o bom funcionamento do mercado financeiro e do setor bancário foi notada durante a crise financeira de 2007. Antes da crise, financiamentos eram disponibilizados para as famílias a baixo custo, mas a rápida inversão das condições de mercado mostrou como a liquidez pode evaporar rapidamente (BIS, 2013). Assim, nota-se a importância de se manter níveis mínimos de capital.

A instituição que concede crédito recebe juros como remuneração pelo capital emprestado, porém deve se atentar para a capacidade de pagamento do tomador, do contrário corre um risco muito alto de não receber o montante emprestado de volta e assim ter graves problemas financeiros. As facilidades determinadas pelo crédito fácil propiciam um excesso 
de compras a prazo, que comprometem a situação financeira das famílias (Caderno de educação financeira, BCB 2013). Dado que a maioria dessas compras implica em pagamento de juros compostos, que fazem com que o recurso inicial cresça exponencialmente há chances de a dívida virar inadimplência, assim o individuo passa a ter seu nome inscrito em um ou mais cadastros de restrição ao crédito.

A flexibilização da política monetária nacional, entre outros fatores, conduziu as taxas de juros no mercado de crédito a patamares historicamente baixos. Os níveis de taxas de juros contribuíram para que se observasse tendência favorável tanto do grau de comprometimento de renda das famílias como dos índices de inadimplência (Relatório de economia bancária e crédito 2012). Erlingsson et al.(2014) concluíram que um acesso mais facilitado ao crédito conduz a um aumento do preço dos ativos, expansão do produto no curto prazo e maior instabilidade da economia, com maior probabilidade de existência de períodos recessivos.

Assim sendo, diante da expansão do acesso ao crédito no Brasil e a preocupação com a gestão do excesso e da escassez no controle da liquidez no sistema financeiro brasileiro, destaca-se a seguinte questão de pesquisa: qual a relação entre o nível de endividamento da população brasileira e o índice de Basiléia das instituições bancárias do Sistema Financeiro Nacional?

Portanto o objetivo do presente artigo é analisar as relações entre o nível de endividamento das famílias brasileiras e o índice de Basiléia divulgado pelos bancos no Brasil, índice que retrata o risco de liquidez que as instituições financeiras apresentam em suas operações. Para tal fim foi aplicada uma análise de séries temporais, para avaliar como o endividamento da população e o índice de Basiléia estão relacionados, compreendendo um intervalo de tempo entre janeiro de 2005 a dezembro de 2013, totalizando 109 observações mensais de cada variável.

\section{Estudos no Brasil}

Na pesquisa da qual resultou este artigo, foi realizada uma pesquisa bibliográfica sobre estudos que envolviam o nível de endividamento das famílias brasileiras e sua eventual relação com a dinâmica do índice de Basiléia no Sistema Financeiro Nacional. Os principais argumentos, relacionados com a pesquisa realizada, são apresentados a seguir.

Almeida et al. (2012) analisaram os efeitos da crise de crédito para os maiores bancos brasileiros, realizando um estudo para compreender quais aspectos estavam envolvidos, e ainda fizeram um levantamento do índice de Basiléia do primeiro trimestre de 2006 até o ultimo trimestre de 2009, para avaliar o impacto no índice e na variação do Balanço Patrimonial que mais contribuiu para as modificações no índice. O trabalho mostrou que há uma influência do risco de crédito na composição dos riscos das instituições financeiras nacionais. No contexto da pesquisa foram observadas as instituições financeiras em três recortes de tempo: período antes da crise (2006-2007), período durante a crise (2008-2009) e período depois da crise (2010-2011).

Outro estudo é de Alencar (2011), que examina se os bancos possuem uma meta para o índice de Basiléia, se há uma velocidade de ajuste, e se esse ajuste é feito primordialmente pelo lado dos ativos ou dos passivos. O autor utilizou o modelo de ajuste parcial de Memmel e Raupach (2010), que lida com o nível de divida dos bancos. Neste trabalho utilizaram-se dados mensais cobrindo o período de julho de 2002 a dezembro de 2010. A base de dados inicial incluiu todos os conglomerados financeiros que possuíam bancos em sua composição, e todos os bancos que não participavam de algum conglomerado na data de dezembro de 2010. Nos diferentes níveis de significância constatou-se que é bastante similar a proporção de bancos grandes e pequenos que perseguem uma dada meta para seu índice de capital, e que 
os bancos de maior porte apresentam metas de índice de capital significativamente menor, do que os bancos pequenos tanto no caso de Basiléia I quanto no de Basiléia II.

Cunha e Lucas (2011) desenvolveram um estudo cujo objetivo foi mostrar como se estruturou a implementação do segundo acordo de Basiléia pelo Banco Central do Brasil. O trabalho concentrou-se em demonstrar estruturalmente a orientação dada pela autoridade monetária brasileira na implementação do acordo. Outro foco do trabalho foi trazer os desdobramentos nas regras prudenciais, e a expectativa de novas estruturas de gestão de risco, com a introdução de gerenciamento de risco de liquidez. Para atingir os objetivos do trabalho foi realizada uma análise do primeiro acordo da Basiléia, apontando as evoluções trazidas pelo mesmo, mas também apontando as deficiências apresentadas no processo de gestão de risco.

Yanaka e Holland (2010) utilizaram a base de dados do Sistema de Informação de Risco de Crédito (SCR) do Banco Central do Brasil e segregaram as operações de pessoas físicas e jurídicas. Eles utilizaram uma amostra de bancos composta pelas 9 maiores instituições financeiras do Consolidado Bancário. Os autores optaram por excluir os dados da Caixa Econômica Federal, assim a amostra foi composta por 8 bancos. A partir das frequências de inadimplência de cada nível de risco os autores calcularam a média ponderada pela exposição em cada data-base para obter as probabilidades de inadimplência. No estudo observou-se que as frequências de inadimplência de pessoa física são substancialmente maiores que de pessoa jurídica, e que a variação da frequência de inadimplência ao longo do tempo, para uma mesma instituição financeira foi baixa.

Gottschalk e Sodré (2006) realizaram um estudo sobre a forma como o Basiléia II foi implementado no Brasil e na Índia com ênfase nos impactos sobre o crédito, especialmente empréstimos as pequenas e medias empresas. Dentre a discussão que surgiu relativa à implementação do Basiléia II no âmbito dos bancos públicos destacam-se as condições que esses bancos efetivamente terão para desenvolver os modelos de mensuração de risco.

Almeida (2005) realizou um trabalho cujo objetivo foi apresentar uma breve discussão a respeito do acordo de Basiléia, e seus impactos no Brasil no que concerne aos modelos de avaliação de crédito que as instituições adotam. Como ponto de partida tomou-se o conceito de criação e de adequação do acordo de Basiléia, que de certa forma, influencia o mercado financeiro mundial. Observou-se que o ponto de maior sensibilidade é certamente o desequilíbrio em relação à capacidade das instituições financeiras, em comparação aos países de primeiro mundo, em administrar um método de classificação interno.

Bertucci, Amaral e Souza (2004), se basearam em dados dos cinco maiores bancos de varejo brasileiros e buscaram investigar se ocorreram alterações nas estruturas de capitais e de ativos nos anos anteriores ao estudo, devido à regulação referente a exigências de capital no contexto do Acordo da Basiléia de 1988. Foram coletados dados dos demonstrativos contábeis dos bancos escolhidos no período de 1990 a 2002, e o estudo se deu pela analise das series temporais obtidas e pela realização de regressões lineares. Utilizaram-se regressões de series temporais, umas nas outras, como forma de verificar o tipo de intensidade da interação existente entre a evolução temporal dessas séries. Cabe destacar a heterogeneidade das características e do comportamento dos bancos brasileiros (confirmada nesse estudo).

Portanto, a pesquisa da qual resulta este artigo é consonante com a análise de Almeida et al. (2012) ao enfatizar o endividamento das famílias sobre o índice de Basiléia. Ainda segundo Cunha e Lucas (2011), na estruturação do acordo de Basileia no Brasil há uma consideração do risco de liquidez, sendo que conforme Yanaka e Holland (2010), na consideração do risco de crédito, verificou-se que frequências de inadimplência de pessoa física são substancialmente maiores do que de pessoa jurídica e, de acordo com Alencar (2011), na dinâmica da gestão de risco do Sistema Financeiro Nacional pode-se constatar a 
adoção de metas no índice de Basiléia, o que é tecnicamente tratado por séries temporais na abordagem metodológica desta pesquisa.

\section{Referencial Teórico}

O sistema financeiro nacional que engloba o Banco Central, bancos comerciais e de investimentos, fundos de pensão, bolsas de valores e companhias de seguro (SILVA, JUNIOR e SILVA, 2006) tem como principal função regulamentar, fiscalizar e executar as operações para circulação da moeda e do crédito na economia. Constituem órgãos de fiscalização: Banco Central do Brasil, Comissão de Valores mobiliários (CVM), Superintendência de Seguros Privados (SUSEP) e a Superintendência Nacional de Previdência Complementar (PREVIC).

Ainda segundo Paula (2013) a teoria moderna da intermediação financeira diz que um sistema financeiro funcional seria aquele que provê a melhor distribuição da informação para guiar consumidores e poupadores na alocação intertemporal da renda e riqueza, contribuindo para superar (parcialmente) a assimetria de informações entre poupadores e investidores, o que contribui para um melhor gerenciamento de risco na atividade de intermediação financeira.

\subsection{Risco de crédito e Risco de Liquidez}

Segundo Mileo, Kimura e Kayo (2013), a quebra das instituições financeiras está associada à ocorrência de inadimplências em massa nos financiamentos; e com a interligação dos sistemas financeiros nacionais, os inadimplementos em massa passaram a ter reflex os em bancos de vários países.

Britto e Assaf Neto (2008) definem o conceito de crédito para uma instituição financeira como à atividade de colocar um valor à disposição de um tomador de recursos sob a forma de um empréstimo ou financiamento, mediante o compromisso de pagamento em uma data futura. Os mesmos autores definem risco de crédito como a possibilidade de o credor incorrer em perdas, em razão de as obrigações assumidas pelo tomador não serem liquidadas nas condições estabelecidas.

Risco de credito trata-se do risco de que a contraparte na transação não honre sua obrigação nos termos e condições do contrato. $\mathrm{O}$ risco de crédito está presente, nas chamadas operações de crédito, como empréstimos e financiamentos, em qualquer outra modalidade representada por instrumentos financeiros que estejam no ativo da instituição, seja nas contas patrimoniais, sejam nas de compensação. (BCB, 2015)

Yurdakul (2014) pontua que o risco mais importantes a que os bancos estão expostos é o risco de crédito, que envolvem empréstimos que podem não ser pagos de volta.

De acordo com Britto e Assaf Neto (2008) a mensuração do risco de crédito é o processo de quantificar a possibilidade de uma instituição financeira incorrer em perdas, caso os fluxos de caixa esperados com as operações de crédito não se confirmem. Todavia Cerri e Britto (2014) afirmam que o risco de crédito não é apenas uma medida da expectativa de perda da instituição, mas é também fundamental para a formação das taxas de juros dos empréstimos pelas instituições financeiras.

Os bancos também estão expostos ao risco de liquidez. Segundo Martins et al.(2012) os bancos são agentes econômicos caracterizados pelo elevado nível de liquidez que é fortemente influenciado por aspectos macroeconômicos, como o cenário internacional, quanto microeconômico, no que concerne as próprias perspectivas de negócios. Ainda segundo eles, os bancos intermediam recursos sobre incertezas e riscos incapazes de serem probabilisticamente auferidos com acurácia. Assim, eles buscam se municiar de instrumentos 
que lhe assegurem, no mínimo, a redução dos efeitos nocivos que a falta de liquidez pode causar sobre suas operações.

Por definição do BCB (2015), risco de liquidez trata-se do risco de a instituição tornarse incapaz de honrar suas obrigações ou de garantir condições para que sejam honradas. Por essa definição ele se separa em dois tipos: risco de liquidez de financiamento, que se refere à capacidade de ajustar desequilíbrios no fluxo de caixa por meio de novas captações de recursos e risco de liquidez de mercado, que se refere à capacidade de liquidação de posições abertas em tempo hábil, na quantidade suficiente e a preço justo.

Segundo Capelletto e Corrar (2008) o risco de liquidez é causado pelos descasamentos de prazos, indexador, moeda e valor entre os pagamentos e recebimentos.

A crise do subprime mostrou como o risco de liquidez pode devastar, de forma rápida e implacável, determinadas formas de financiamento, aumentando a preocupação dessas instituições com a valorização de seus ativos e a adequada quantidade de capital necessário para manter o "colchão" que deve lastrear suas operações (MARTINS et al., 2012).

A falta de liquidez obriga a rápida realização de ativos e provoca a queda dos preços desvalorizando ativos iguais ou semelhantes detidos por outras instituições. A constatação desse fato pelos depositantes pode provocar saques inadvertidos e gerar a "corrida bancaria", que constitui importante preocupação das autoridades monetárias (CAPELLETTO e CORRAR, 2008). Assim a falta de liquidez em alguma instituição financeira pode gerar instabilidade em todo o sistema financeiro.

\subsection{O Endividamento familiar}

O aumento no nível de endividamento é uma questão que tem se tornado cada vez mais importante no cenário econômico brasileiro e também mundial, pois aumentando o nível de endividamento aumenta-se o risco dos endividados não conseguirem honrar seus compromissos ate o vencimento (o que os torna inadimplentes). Ruberto et al.(2013) afirmam que a inadimplência é consequência natural do processo de endividamento. Pinto e Coronel (2013) concordam com essa ideia ao dizer que a redução do endividamento deve ser considerada como prioridade tanto pela população quanto pelos órgãos públicos, pois dele derivam o superendividamento e a inadimplência. Caju et al. (2014) discutem que a elevação de um índice de dívida pode ter implicações significativas para a volatilidade das atividades macroeconômicas e possivelmente para a estabilidade financeira se a posição da dívida tornase insustentável.

Pela importância do tema alguns autores estudam os fatores que levam ao endividamento, sendo apontados fatores financeiros e não financeiros. Keese (2012) e Caju et al. (2014) apontam a expectativa com rendimentos futuros como uma das causas do endividamento. Caju et al. (2014) discutem que na pratica a situação da renda futura é muitas vezes desconhecida, e podem ocorrer grande choques econômicos adversos, como uma aumento do desemprego, a queda no preço dos ativos ou uma redução na produtividade e todos esses fatores podem se tornar persistentes. Estes choques podem revelar que o nível de endividamento é baseado em uma sobre-estimativa de renda permanente, e constitui o excesso de dívida. Vieira, Roma e Ferreira (2014) destacam que a maior facilidade de contratação de crédito associada com a escolha por obrigações situadas cada vez mais no longo prazo, ampliou o índice de endividamento familiar (proporção ente o valor total de dividas e a renda das famílias brasileiras). Costa e Farinha (2012) afirmam que as decisões de consumo e investimento das famílias e consequentemente as suas decisões de endividamento dependem da fase do ciclo de vida, dos membros da família, do seu rendimento e da sua riqueza, nível de escolaridade e condição perante o trabalho, esses fatores também influenciam a decisão dos credores em conceder ou não credito. 
Além de desconforto para um individuo ou família, um nível de endividamento elevado pode ter efeitos negativos para a economia como um todo. Em termos macroeconômicos um nível de endividamento elevado pode tornar o consumo das famílias mais sensíveis a choques da taxa de juro e renda. No caso de uma falência financeira estes choques também podem desencadear uma tendência de desalavancagem que por sua vez e suscetível de reforçar a espiral de declínio econômico. Além disso, os níveis de endividamento excessivo podem prejudicar a estabilidade financeira, pois a incapacidade de honrar seus compromissos leva a uma perda de valor para os credores, muitas vezes concentrados no setor bancário, principalmente no caso da dívida das famílias (CAJU et al., 2014).

Cabe ainda destacar que segundo Brown et al.(2013) muitos apontam que o inicio da crise econômica de 2008 se deu no mercado de hipotecas residenciais com um número cada vez maior de tomadores de empréstimos tornando-se inadimplentes. E por isso o endividamento das famílias tem se tornado objetivo de interesse. No estudo Brown et al.(2013) observaram um aumento substancial nos níveis de endividamento do consumidor de 1999 até 2008 nos Estados Unidos. Ainda segundo o estudo o que provocou essas mudanças foi a dívida com imóveis residenciais, que representava a maioria das responsabilidades das famílias.

\subsubsection{A dívida das famílias brasileiras}

A Pesquisa de Endividamento e Inadimplência do Consumidor (PEIC) mostra que, o percentual de famílias que relataram ter dívidas entre cheque pré-datado, cartão de crédito, cheque especial, carnê de loja, empréstimo pessoal, prestação de carro e seguro alcançou $62,7 \%$ em fevereiro de 2014, recuando em relação aos 63,4\% observados em janeiro de 2014 e aumentando em relação aos 61,5\% de fevereiro de 2013. O nível de endividamento seguiu apresentando alta na comparação anual. (CNC - confederação nacional do comercio /2014).

$\mathrm{O}$ endividamento das famílias com dividas bancaria teve leve aumento no segundo semestre de 2013, atingindo 45,5\% em dezembro de 2013. Já o comprometimento de renda das famílias com dívidas bancárias apresentou leve redução em 2013, alcançando 21,6\% em dezembro, ante $21,8 \%$ doze meses antes.

Esse comportamento é explicado por uma melhora no perfil do endividamento, associado ao aumento de participação de modalidades com prazos mais longos e taxas e prestações menores, especialmente financiamento habitacional e crédito consignado. A tendência de melhora no perfil das dívidas é reforçada pelo desempenho de modalidades com taxas de juros elevadas, como o cheque especial e o crédito rotativo de cartão de crédito, que cresceram menos que o aumento da renda (Relatório de estabilidade financeira - BCB /2014).

O tempo médio de comprometimento com dívidas, entre as famílias endividadas foi de 6,9 meses, sendo que $24,7 \%$ estão comprometidas com dívidas de até três meses, e 30,3\%, por mais de um ano. Ainda entre as famílias endividadas, a parcela média da renda comprometida com dívidas aumentou na comparação anual, passando de 29,0\% para 30,9\%; e 22,5\% delas afirmaram ter mais da metade de sua renda mensal comprometida com pagamento de dívidas. (PEIC-CNC /2014).

A taxa média de juros das operações de crédito do sistema financeiro nacional atingiu $21,4 \%$ a.a. em maio de 2014 (21\% a.a. em fevereiro e 18,1\% a.a. em maio de 2013). O aumento trimestral de 0,4 p.p. refletiu elevações respectivas de 0,4 p.p. e 0,8 p.p. nas taxas praticadas nos segmentos de crédito com recursos livres e com recursos direcionados, que se situaram, na ordem, em $32 \%$ a.a. e 8,4\% a.a., em maio. A taxa de juros atingiu 27,9\% a.a. no segmento de pessoas físicas (aumentos de 0,5 p.p. no trimestre e 3,9 p.p. em doze meses). (Relatório de inflação - BCB /2014). 


\subsection{O Acordo da Basiléia}

Criado em 1930, o Banco de Compensações Internacionais (BIS) atua como um agente de cooperação para os bancos centrais, fornecendo aporte financeiro emergencial em caso de crises que ameacem o sistema financeiro internacional como um todo. Em 1975, foi estabelecido o Comitê de Supervisão Bancária da Basiléia, (BCBS), ligado ao BIS e formado pelos bancos centrais dos países integrantes do Grupo dos Dez (G10) (Manual da supervisão $\mathrm{BCB} / 2009)$.

O Comitê de Basiléia é o primeiro padrão global para a regulação prudencial dos bancos e proporciona um fórum para a cooperação em matéria de supervisão bancária. $\mathrm{O}$ seu mandato é para reforçar a regulação, supervisão e práticas de bancos em todo o mundo com o objetivo de reforçar a estabilidade financeira.

Em 1988 se divulgou o primeiro Acordo de Capital de Basiléia, com o objetivo de criar exigências mínimas de capital para instituições financeiras, como forma de fazer face ao risco de crédito (Manual da supervisão BCB/2009). O acordo previa capital mínimo para ativos ponderados pelo risco de $8 \%$ a serem implementadas até o final de 1992 (BIS/2013). A implementação do acordo de 88 no Brasil, se deu por meio da Resolução no 2.099, de 17 de agosto de 1994. Ela introduziu no país exigência de capital mínimo para as instituições financeiras que varia em função do grau de risco de suas operações ativas (Manual da supervisão BCB/2009).

Em 1996, o Comitê publicou uma emenda ao Acordo de 88, incorporando ao capital exigido uma parcela para cobertura dos riscos de mercado.

Com o intuito de obter uma medida mais precisa dos riscos incorridos pelos bancos internacionalmente ativos, o BCBS divulgou revisão do Acordo de Capital da Basiléia em 2004, conhecida como Basiléia II. No Basiléia II, são cobertos explicitamente três tipos de risco: de credito, de mercado e operacional.

O quadro "Basiléia II" revisto compreendia três pilares, a saber, (BIS/2013):

- Requisitos mínimos de capital, que procuraram desenvolver e expandir as regras padronizadas estabelecidas no Acordo de 1988;

- Revisão e adequação de capital de uma instituição e processo de avaliação interna de fiscalização;

- Uso eficaz de divulgação como uma alavanca para fortalecer a disciplina do mercado e incentivar boas práticas bancárias.

Como consequência da crise financeira ocorrida em 2008, o Comitê de Basiléia emitiu em 2009 os documentos Melhorias no quadro de Basiléia II e Revisões para o Basiléia II quadro de risco. Através desses documentos, dentre outras medidas, foram estabelecidos: pesos maiores para determinadas operações de securitização, alterações na mensuração do risco de mercado, bem como consideração de cenários estressados para a avaliação de risco. As novas orientações visaram suprir lacunas identificadas no processo de gestão de risco dos bancos durante a crise.

O Comitê de Basiléia publicou novo conjunto de recomendações para fortalecer a regulação, supervisão e gestão de risco da indústria bancária em dezembro de 2010. Essas novas recomendações objetivaram, aperfeiçoar a capacidade das instituições financeiras absorverem choques provenientes do sistema financeiro ou dos demais setores da economia e, ainda, reduzir o risco de contágio do setor financeiro sobre o setor real da economia (Manual da supervisão BCB/2009). Para tal, foram determinadas: 
a) Composição mais rigorosa de capital;

b) Harmonização internacional de ajustes regulamentares sobre capital;

c) Ampliação dos procedimentos de transparência dos elementos que compõem o capital;

d) Implementação de Índice de alavancagem a ser aplicado como medida complementar ao requerimento mínimo de capital;

e) Criação de duas modalidades de capital (buffers): uma com a finalidade de absorver perdas em períodos de estresse (amortecedores de conservação de capital) e a outra para absorver perdas decorrentes de alterações no ambiente macroeconômico (amortecedor anticíclico);

f) Requerimentos mínimos quantitativos para a liquidez de instituições financeiras.

O quadro abaixo mostra os pilares que estruturam o Basiléia III: 
Quadro 1 - Pilares que estruturam o Basiléia III

Comitê de Basileia de Supervisão Bancária reformas - Basiléia III

Fortalece a regulação e supervisão microprudencial, e adiciona uma sobreposição macroprudencial que inclui amortecedores de capital.

\begin{tabular}{|c|c|c|c|c|}
\hline \multicolumn{5}{|l|}{ CAPITAL } \\
\hline \multicolumn{3}{|l|}{ Pilar 1} & Pilar 2 & Pilar 3 \\
\hline Capital & Cobertura de risco & Contendo influência & Gestão de risco e supervisão & Disciplina de mercado \\
\hline $\begin{array}{l}\text { Qualidade e nível de capital } \\
\text { Maior foco sobre patrimônio } \\
\text { comum. O mínimo será elevado } \\
\text { para } 4,5 \% \text { de ativos ponderados } \\
\text { pelo risco, após deduções. } \\
\text { Absorção de perdas de capital } \\
\text { no ponto de inviabilidade } \\
\text { Cláusulas contratuais dos } \\
\text { instrumentos de capital incluirão } \\
\text { uma cláusula que permite- a } \\
\text { critério de autoridade } \\
\text { competente- baixa ou conversão } \\
\text { em ações ordinárias se o banco é } \\
\text { considerado inviável. Este } \\
\text { princípio aumenta a contribuição } \\
\text { do setor privado para resolver } \\
\text { futuras crises bancárias e assim, } \\
\text { reduz o risco moral. }\end{array}$ & $\begin{array}{l}\text { Securitizações } \\
\text { Fortalece o tratamento de capital } \\
\text { para determinadas securitizações } \\
\text { complexas. Obriga os bancos a } \\
\text { realizar análises de crédito mais } \\
\text { rigorosas de securitizações } \\
\text { externas. } \\
\text { Carteira de negociação } \\
\text { Significante parcela de capital } \\
\text { para negociações e derivativos, } \\
\text { bem como securitizações } \\
\text { complexas detidas na carteira de } \\
\text { negociação. Introdução de um } \\
\text { quadro salientado em valor-a- } \\
\text { risco para ajudar a reduzir a pró- } \\
\text { ciclicidade. Uma parte de capital } \\
\text { para estimativas de risco de } \\
\text { inadimplência e de migração de } \\
\text { produtos de crédito não titulados } \\
\text { que leva em conta a liquidez. }\end{array}$ & $\begin{array}{l}\text { Índice de alavancagem } \\
\text { Um rácio de alavancagem não } \\
\text { baseado em risco, que inclui } \\
\text { exposições extrapatrimoniais } \\
\text { servirá como uma barreira para a } \\
\text { exigência de capital com base no } \\
\text { risco. Também ajuda a conter } \\
\text { todo o sistema de grande } \\
\text { acumulação de alavancagem. }\end{array}$ & 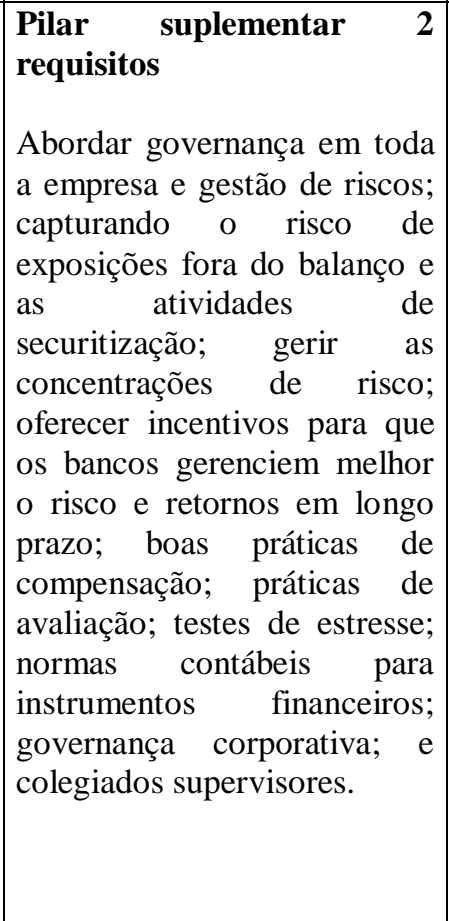 & $\begin{array}{lr}\begin{array}{l}\text { Pilar 3 revisado: } \\
\text { exigências de divulgação }\end{array} \\
\text { As } & \text { exigências } \\
\text { introduzidas } & \text { dizem } \\
\text { respeito às posições de } \\
\text { securitização e patrocínio } \\
\text { de veículos fora do } \\
\text { balanço. Divulgações } \\
\text { sobre os detalhes dos } \\
\text { componentes do capital } \\
\text { regulamentar e sua } \\
\text { reconciliação com as } \\
\text { contas reportadas serão } \\
\text { necessários, incluindo } \\
\text { uma explicação detalhada } \\
\text { de como o banco calcula } \\
\text { os seus rácios de capital } \\
\text { regulamentar. }\end{array}$ \\
\hline
\end{tabular}




\begin{tabular}{|c|c|c|c|}
\hline Capital & Cobertura de risco & $\begin{array}{c}\text { SIFs - Instituições financeiras } \\
\text { sistemicamente importantes globais }\end{array}$ & LIQUIDEZ \\
\hline $\begin{array}{l}\text { Amortecedores de } \\
\text { conservação de capital } \\
\text { Composto por ações } \\
\text { ordinárias de } 2,5 \% \text { de ativos } \\
\text { ponderados pelo risco, } \\
\text { elevando o padrão total de } \\
\text { patrimônio comum para } 7 \% \text {. } \\
\text { Restrição em distribuições } \\
\text { discricionárias de um banco } \\
\text { será imposta quando os } \\
\text { bancos se enquadram na } \\
\text { faixa de buffer. } \\
\text { Amortecedor anticíclico } \\
\text { Imposta no intervalo de } 0- \\
2,5 \% \text { compreendendo ações } \\
\text { ordinárias, quando } \\
\text { autoridades julgarem que o } \\
\text { crescimento do crédito está } \\
\text { resultando em uma } \\
\text { acumulação inaceitável de } \\
\text { risco sistêmico. }\end{array}$ & $\begin{array}{l}\text { Risco } \text { de } \\
\text { contraparte }\end{array}$ & $\begin{array}{l}\text { Além de atender os requisitos de Basileia } \\
\text { III, as instituições financeiras } \\
\text { sistemicamente importantes globais (SIFIs) } \\
\text { devem ter maior capacidade de absorção de } \\
\text { perdas para refletir os maiores riscos que } \\
\text { eles representam para o sistema financeiro. } \\
\text { A Comissão desenvolveu uma metodologia } \\
\text { que inclui os indicadores quantitativos e } \\
\text { qualitativos, elementos para identificar os } \\
\text { bancos globais sistemicamente importantes } \\
\text { (SIBS). Os requisitos adicionais de perda de } \\
\text { absorção devem ser atendidos com uma } \\
\text { camada progressiva do Patrimônio Comum } \\
1 \text { (CET1) exigência de capital que varia de } \\
1 \% \text { a 2,5\%, dependendo da importância } \\
\text { sistêmica do banco. Para os bancos que } \\
\text { enfrentam a maior sobretaxa SIB, uma } \\
\text { perda adicional, absorção de } 1 \% \text { pode ser } \\
\text { aplicada como um desincentivo para } \\
\text { aumentar sensivelmente a sua importância } \\
\text { sistêmica global no futuro. Um documento } \\
\text { de consulta foi publicado em cooperação } \\
\text { com o Conselho de Estabilidade Financeira, } \\
\text { que está coordenando o conjunto global de } \\
\text { medidas para reduzir o risco moral } \\
\text { representada pelas SIFIs globais. }\end{array}$ & $\begin{array}{l}\text { A liquidez global padrão e o monitoramento de supervisão } \\
\text { Rácio de cobertura de liquidez } \\
\text { O rácio de cobertura de liquidez (LCR) vai exigir que os } \\
\text { bancos tenham ativos líquidos de alta qualidade, suficientes } \\
\text { para resistir a um cenário financeiro de estresse, de } 30 \text { dias } \\
\text { que é especificada pelos supervisores. } \\
\text { Rácio de financiamento estável Net } \\
\text { O rácio de financiamento estável net (NSFR) é uma relação } \\
\text { estrutural de longo prazo projetado para atender } \\
\text { descasamentos de liquidez. Abrange todo o balanço e prevê } \\
\text { incentivos para que os bancos utilizam fontes estáveis de } \\
\text { financiamento. } \\
\text { Princípios para uma boa gestão de Risco de Liquidez e } \\
\text { Supervisão } \\
\text { Princípios de orientação do Comitê de } 2008 \text { : Gestão de } \\
\text { Risco de Liquidez e Supervisão tem em conta as lições } \\
\text { aprendidas durante a crise e é baseado em uma revisão } \\
\text { fundamental das boas práticas para o gerenciamento de } \\
\text { risco de liquidez em organizações bancárias. } \\
\text { Monitoramento e supervisão } \\
\text { O quadro de liquidez inclui um conjunto comum de } \\
\text { métricas de monitoramento para auxiliar os supervisores na } \\
\text { identificação e análise de tendências de risco de liquidez, } \\
\text { tanto no banco como no nível de todo o sistema. }\end{array}$ \\
\hline
\end{tabular}

Fonte: Traduzido de http://www.bis.org/bcbs/basel3/b3summarytable.pdf 


\subsection{1 Índice de Basiléia}

Definido pelo acordo de Basiléia de 1988 o índice mínimo de capital para cobertura do risco de crédito (índice de Basiléia ou índice de adequação de capital) é o quociente entre o capital regulatório e os ativos (dentro e fora do balanço) ponderados pelo risco.

O Comitê de Basiléia recomenda uma relação mínima de $8 \%$ entre o Capital Base (Patrimônio de Referência - PR) e os riscos ponderados conforme a regulamentação em vigor (Patrimônio Líquido Exigido - PLE).

Patrimônio de Referência (PR) é a medida de capital regulamentar utilizada para fins da verificação do cumprimento dos limites operacionais das instituições financeiras e demais instituições autorizadas a funcionar pelo Banco Central do Brasil. Nos termos da Resolução n. ${ }^{\circ}$ 3.444, de 28 de fevereiro de 2007, o Patrimônio de Referência é composto basicamente pelo somatório do capital de nível I e do capital de nível II, com as deduções previstas naquele instrumento normativo. (BCB, 2013)

Patrimônio de Referência Exigido (PRE) é o patrimônio exigido das instituições financeiras, decorrente dos riscos a que estão expostas, em função das atividades por elas desenvolvidas. É calculado de acordo com a regulamentação em vigor, alcançando os registros nas contas ativas, passivas e de compensação. Atualmente é definido pela Resolução 3.490 , de 29 de agosto de 2007, e suas regulamentações posteriores. O PRE é calculado a partir da soma das parcelas de patrimônio exigido para a cobertura das exposições aos diversos riscos. (BCB, 2013).

No Brasil, a relação mínima exigida é dada pelo fator $\mathrm{F}$, de acordo com a Resolução n..$^{\circ} 3.490$, de 29 de agosto de 2007, e Circular n. ${ }^{\circ} 3.360$, de 12 de setembro de 2007, devendo ser observados os seguintes valores:

a) 0,11 (onze centésimos), tratando-se de instituições financeiras e demais instituições autorizadas a funcionar pelo Banco Central do Brasil, exceto cooperativas de crédito não filiadas a cooperativas centrais de crédito;

b) 0,15 (quinze centésimos), tratando-se de cooperativas de crédito singulares não filiadas a cooperativas centrais de crédito.

Obs.: Caso as cooperativas singulares de crédito se utilizarem da faculdade prevista no Art. $2^{\circ}, \S 4^{\circ}$, da Resolução $n^{\circ} 3.490 / 2007$, elas deverão adicionar 0,02 (dois centésimos) ao fator F.

O cálculo do índice é efetuado de acordo com a seguinte fórmula:

$$
P R \times 100 / \frac{P R E}{\text { Fator F }}
$$

Considera-se desenquadrada em relação ao Índice de Basiléia a instituição cujo Patrimônio de Referência (PR) seja inferior ao Patrimônio de Referência Exigido (PRE) calculado para ela, isto é, seu patrimônio é insuficiente para a cobertura dos riscos decorrentes de suas operações ativas, passivas e registradas em contas de compensação. (BCB, 2013)

O acordo de Basiléia e suas imposições visam manter um nível mínimo de solvência dos bancos comerciais a nível internacional. Sbârcea em seu estudo exemplificou dizendo que um aumento acelerado da carteira de crédito (ativos que possuem $100 \%$ de risco) deve ser acompanhado de um aumento de capital, porque uma queda do indicador de adequação de capital, para menos de $8 \%$, não é suportada pela autoridade bancária de supervisão. Assim esse indicador tem a intenção de manter o capital dos bancos em um nível mínimo acordado (SBÂRCEA, 2014). 
Segundo Bateni et al. (2014) índices mínimos de adequação de capital fazem a promoção da estabilidade e eficiência do sistema financeiro, diminuindo a probabilidade de insolvência em bancos.

Abaixo estão descritos alguns estudos que buscaram apontar algumas das que variáveis influenciam o índice.

Bateni et al. (2014), estudaram as relações entre os índices financeiros e o índice de adequação de capital, com o objetivo de analisar e avaliar os fatores influentes do índice nos banco iranianos. Utilizando dados em painel analisou a relação entre variáveis bancarias especificas, e concluiu que o tamanho do banco impacta negativamente o índice, por outro lado ROA (retorno sobre ativo), ROE (retorno sobre patrimônio) e LAR (empréstimos em relação ao ativo) afetam positivamente o índice de adequação de capital nos bancos do Irã.

Abba et al.(2013), objetivando investigar empiricamente a relação entre riscos e o índice de adequação de capital na Nigéria, realizaram um estudo no período de cinco anos (2007-2011), utilizando um modelo de regressão múltipla e concluíram que existem evidências empíricas e estatísticas sobre a relação entre adequação de capital e risco das agências bancárias, sendo essa relação negativa para os bancos da Nigéria.

Bokhari, Ali e Sultan (2012) analisaram os determinantes do índice de Basiléia nas instituições bancárias do Paquistão, para isso coletaram dados anuais no período de 2005 2009, utilizando o modelo de regressão pooled concluíram que as variáveis: exigência de regulação, produto interno bruto (PIB), e índice médio do setor possuem correlação positiva com o índice de Basiléia, no entanto as variáveis: risco portfólio, retorno sobre patrimônio liquido e parcelas de depósitos possuem correlação negativa com o índice.

Abusharba et al.(2013) estudaram alguns fatores internos que tem impacto sobre o índice de adequação de capital em bancos islâmicos na Indonésia. Foram utilizados dados mensais do período de 2009 a 2011. Utilizando regressões múltiplas os resultados indicaram que o financiamento não realizado é negativamente correlacionado com o índice, estrutura de depósitos e liquidez está positivamente correlacionado, e rentabilidade (ROA) também tem um efeito positivo sobre o índice. Concluíram que quanto maior a liquidez de um banco islâmico maior o índice de adequação de capital.

\section{Metodologia}

O estudo será quantitativo, pois pretende analisar as relações estatísticas existentes entre o endividamento das famílias brasileiras e o índice de Basiléia divulgado pelos bancos. Foi realizada pesquisa bibliográfica para se ter conhecimento de alguns estudos que já haviam sido publicado sobre o assunto no Brasil.

Na pesquisa foi utilizada base de dados mensal disponível no site do Banco Central do Brasil que informa o índice de Basiléia durante o período de janeiro de 2005 a dezembro de 2013. A análise dos dados foi feita por meio de séries temporais.

O quadro abaixo explicita os dados utilizados na pesquisa e a descrição de cada um deles.

Quadro 2 - Descrição dos dados do modelo

\begin{tabular}{|c|c|}
\hline Dados & Descrição \\
\hline $\begin{array}{l}\text { Índice de Basiléia } \\
\text { (Índice de Adequação de Capital) }\end{array}$ & $\begin{array}{l}\text { Conceito internacional definido pelo Comitê de Basiléia que } \\
\text { recomenda a relação mínima de } 8 \% \text { entre o Patrimônio de Referência } \\
\text { (PR) e os riscos ponderados conforme regulamentação em vigor } \\
\text { (Patrimônio de Referência Exigido - PRE). No Brasil, a relação } \\
\text { mínima exigida é dada pelo fator F, de acordo com a Resolução do } \\
\text { CMN no } 3.490 \text {, de } 29 \text { de agosto de } 2007 \text {, e Circular do BC n }{ }^{\circ} 3.360 \text {, } \\
\text { de } 12 \text { de setembro de } 2007 \text {, devendo ser observados os seguintes } \\
\text { valores: }\end{array}$ \\
\hline
\end{tabular}




\begin{tabular}{|c|c|}
\hline $\begin{array}{l}\text { Índice de Basiléia } \\
\text { (Índice de Adequação de Capital) }\end{array}$ & $\begin{array}{l}\text { a) } 0,11 \text { (onze centésimos), para as instituições financeiras e as demais } \\
\text { instituições autorizadas a funcionar pelo BC, exceto cooperativas de } \\
\text { crédito não filiadas a cooperativas centrais de crédito; e } \\
\text { b) } 0,15 \text { (quinze centésimos), para cooperativas de crédito singulares } \\
\text { não filiadas a cooperativas centrais de crédito. } \\
\text { Obs.: As cooperativas de crédito singulares que utilizarem a } \\
\text { faculdade prevista no art. } 2^{\circ} \S 4^{\circ} \text {, da Resolução do CMN n } 3.490 \text {, } \\
\text { de } 2007 \text {, devem adicionar } 0,02 \text { (dois centésimos) ao fator F. } \\
\text { O cálculo do índice é efetuado de acordo com a seguinte fórmula: } \\
\text { PR*100 / (PRE/fator F) } \\
\text { PR: Patrimônio de Referência } \\
\text { PRE: Patrimônio de Referência Exigido (BCB/2013) }\end{array}$ \\
\hline Endividamento & $\begin{array}{l}\text { O indicador de endividamento é obtido dividindo-se a dívida das } \\
\text { famílias pela Massa Salarial Ampliada Disponível (MSAD) dos } \\
\text { últimos doze meses. (Relatório de estabilidade financeira - BCB } \\
\text { /2014). }\end{array}$ \\
\hline Inflação IPCA & $\begin{array}{l}\text { O IPCA (índice nacional de preços ao consumidor amplo) tem por } \\
\text { objetivo medir a inflação de um conjunto de produtos e serviços } \\
\text { comercializados no varejo, referentes ao consumo pessoal das } \\
\text { famílias, cujo rendimento varia entre } 1 \text { e } 40 \text { salários mínimos, } \\
\text { qualquer que seja a fonte de rendimentos. } \\
\text { Desde junho de 1999, é o índice utilizado pelo Banco Central do } \\
\text { Brasil para o acompanhamento dos objetivos estabelecidos no sistema } \\
\text { de metas de inflação, sendo considerado o índice oficial de inflação } \\
\text { do país. (IBGE /2006) }\end{array}$ \\
\hline Taxa Selic & $\begin{array}{l}\text { Define-se Taxa Selic como a taxa média ajustada dos } \\
\text { financiamentos diários apurados no Sistema Especial de Liquidação e } \\
\text { de Custódia (Selic) para títulos federais. Para fins de cálculo da taxa, } \\
\text { são considerados os financiamentos diários relativos às operações } \\
\text { registradas e liquidadas no próprio Selic e em sistemas operados por } \\
\text { câmaras ou prestadores de serviços de compensação e de liquidação } \\
\text { (art. } 1^{\circ} \text { da Circular } n^{\circ} 2.900 \text {, de } 24 \text { de junho de } 1999 \text {, com a alteração } \\
\text { introduzida pelo art. } 1^{\circ} \text { da Circular } n^{\circ} 3.119 \text {, de } 18 \text { de abril de 2002). }\end{array}$ \\
\hline Inadimplência no SPC & $\begin{array}{l}\text { Novos registros - Indicador que registra a quantidade (fluxo) mensal } \\
\text { de anotações de inadimplência das pessoas físicas que compõem a } \\
\text { base de dados do SPC. } \\
\text { Registros cancelados - Indicador que registra a quantidade (fluxo) } \\
\text { mensal de anotações de pessoas físicas que saíram da inadimplência. }\end{array}$ \\
\hline
\end{tabular}

Fonte: Elaborado pelos autores

\subsection{Estimação do modelo}

Foi utilizado o método Autoregressive Conditional Heteroskedasticity (ARCH) para estimação do nosso modelo (esse método esta descrito na próxima subseção). A amostra considerada na pesquisa, em função da disponibilidade de dados, compreendeu o período de abril de 2005 a dezembro de 2013.

$\mathrm{Na}$ estimação foi utilizada como variável depende o logaritmo do índice de Basiléia (LOG(IB)), e como variável explicativa o logaritmo do endividamento (LOG(END)). 
Realizou-se o teste d de Durbin-Watson para a detecção de correlação serial nos termos de erro. Sua definição é:

$$
d=\frac{\sum_{t=2}^{t=n}\left(\hat{u}_{t}-\hat{u}_{t-1}\right)^{2}}{\sum_{t=1}^{t=n} \hat{u}_{t}^{2}}
$$

Porém pode-se expressar a estatística como:

$$
d \approx 2(1-\rho) \quad-1 \leq \rho \leq 1
$$

Se $\rho=0, d=2$ e assim conclui-se que não há correlação serial. Portanto espera-se que a estatística d fique em torno de 2.

Foram realizados testes para verificação da presença de raiz unitária. Os testes de raiz unitária verificam a estacionaridade (ou não estacionaridade) da série temporal. Para nosso modelo foi utilizado o teste de Dickey-Fuller aumentado. Teste conduzido por meio do "aumento" das equações pelo acréscimo dos valores defasados da variável dependente $\Delta y_{t}$.

$$
\Delta y_{t}=\beta_{1}+\beta_{2} t+\delta y_{t-1}+\sum_{i=1}^{m} \alpha_{i} \Delta y_{t-1}+\varepsilon_{t}
$$

Temos:

H0: $\delta=0$, existe uma raiz unitária (série não estacionária).

Ha: $\delta<0$, série é estacionaria.

Quando a hipótese de que $\delta=0$ é rejeitada (série temporal é estacionária), pode-se utilizar o teste t de Student usual.

O número de termos de diferenças defasadas a ser incluído, é muitas vezes determinado empiricamente, sendo que a idéia é incluir um número de termos suficiente para que o termo de erro não apresente correlação serial (GUJARATI, 2011). Foi realizado o teste utilizando 0 defasagens, depois 2 defasagens e por ultimo 10 defasagens.

\subsection{Modelo}

Foi utilizado o modelo ML-ARCH (Marquardt). Alguns detalhes do modelo estão descritos a seguir.

Um pressuposto assumido pelo modelo é que a volatilidade, isto é, a variância é homocedástica. Ser homocedástico significa dizer, de uma maneira simples, que a variância é constante ao longo do tempo. Entretanto, o que novamente as evidências dão suporte é a uma teoria em que a "variância varia", havendo, portanto, a presença da heterocedasticidade. Portanto, o desenvolvimento de modelos que incorporassem essas características foi sendo cada vez mais necessário.

Engle (1982) formulou o Autoregressive Conditional Heterecesdasticity (ARCH), que é um modelo não linear na variância. Deve-se salientar que no caso do ARCH, pode ser necessária uma quantidade suficiente de lags, isto é, defasagens, tornando o q muito alto. Um modelo ARCH (q) matematicamente descrito é apresentado em Morettin e Toloi (2006) e encontra-se abaixo. Ressalta-se que no próximo modelo apresentado que é uma extensão do $\mathrm{ARCH}$, as expressões foram retiradas desses mesmos autores. 


$$
\begin{gathered}
\mathrm{X}_{t}=\sqrt{h_{t}} \varepsilon_{t} \\
h_{t}=\alpha_{0}+\alpha_{1} \mathrm{X}_{t-1}^{2}+\ldots+\alpha_{r} \mathrm{X}_{t-r}^{2} \\
\varepsilon \sim N(0,1) \text { ou } t_{v} \text { (distribuição T de Student) }
\end{gathered}
$$

Neste modelo, $\mathrm{X}_{t}$ corresponde aos retornos, $\varepsilon_{t}$ refere-se a uma sequência de variáveis aleatórias que são independentes e identicamente distribuídas tendo média zero e variância um e que $\alpha_{0}>0, \alpha_{i} \geq 0$ e $i>0$, explicam Morettin e Toloi (2006, p.363). Na segunda equação, Engle (1982) formulou o ARCH entendendo a variância em função dos erros quadráticos passados.

Entretanto, apesar da inovação do modelo, este ainda pode não refletir todas as necessidades peculiares das finanças, pois como os erros são elevados ao quadrado, não há como diferenciar os impactos dos choques positivos e negativos, e sendo assim, a característica assimetria não é atendida até aquele momento.

Então, em 1986, o modelo Generalized Autoregressive Conditional Heterecesdaticity (GARCH) é proposto por Bollerslev. Tal modelo possui a característica de estimar a volatilidade com menos parâmetros, isto é, é mais parcimonioso. Um modelo GARCH $(p, 1)$ é definido na literatura como:

$$
\begin{gathered}
\mathrm{X}_{t}=\sqrt{h_{t}} \varepsilon_{t} \\
h_{t}=\alpha_{0}+\sum_{i=1}^{p} \alpha_{i} \mathrm{X}_{t-i}^{2}+\sum_{j=1}^{q} \beta_{j} h_{t-j}
\end{gathered}
$$

$\varepsilon \sim N(0,1)$ ou $t_{v}$ (distribuição T de Student com $v$ graus de liberdade)

Aqui, $\varepsilon_{t}$ tem o mesmo significado do $\mathrm{ARCH}$, isto é, são variáveis aleatórias i.i.d com média zero e variância um, $\alpha_{0}>0, \alpha_{i} \geq 0, \beta_{j} \geq 0, \sum_{\mathrm{i}=1}^{\mathrm{q}_{\mathrm{i}}}\left(\alpha_{i}+\beta_{j}\right)<1$ e $q=\max (\mathrm{p}, \mathrm{q})$, conforme descrevem Morettin e Toloi (2006, p.383). Como pode se perceber, o GARCH introduz que a variância no determinado período de tempo (t), e não somente dependente dos erros quadráticos passados, mas também é composta pela própria variância passada.

\section{Resultados}

Os resultados demonstram que o índice de Basiléia, e o nível de endividamento das famílias possuem correlação negativa, o que faz com que os dois variem em sentidos opostos. A tabela abaixo mostra os resultados da regressão.

Tabela 1 - Resultado da regressão

\begin{tabular}{ccccc}
\hline \multicolumn{5}{c}{ GARCH $=\mathrm{C}(7)+\mathrm{C}(8) * \mathrm{GARCH}(-1)$} \\
\hline Coeficiente & Erro-padrão & Estatística-Z & Probabilidade \\
\hline LOG(END) & $-2,165965$ & 0,171162 & $-12,654490$ & 0,0000 \\
D(LOG(IB),2) & 0,220301 & 0,011119 & 19,812590 & 0,0154 \\
AR(1) & 0,976329 & 0,014061 & 69,432880 & 0,0000 \\
MA(1) & 0,398012 & 0,106111 & 3,750889 & 0,0000 \\
MA(2) & $-0,570341$ & 0,105396 & $-5,411388$ & 0,0000 \\
\hline
\end{tabular}

Fonte: Resultados do modelo

Da Silva, S. E.; Ferreira, B. P. 
Trata-se de um resultado consistente visto que um índice de Basiléia elevado significa que o banco tem capacidade de cumprir suas obrigações- mesmo em situações adversas de inadimplência. Mostrando que o banco possui liquidez.

Dado que quanto menor o nível de endividamento das famílias menor a chance das mesmas se tornarem inadimplentes, é de se esperar que a diminuição em um dos índices aumente o outro e vice-versa.

Além disso, uma das atitudes dos bancos para aumentar a liquidez, consiste em racionamento do crédito. A restrição de acesso ao crédito diminui o número de famílias endividadas diminuindo também a probabilidade de inadimplementos.

$\mathrm{Na}$ análise dos resíduos da regressão, o gráfico de previsões de variância demonstrou que a partir de 2006 a variância tende a se estabilizar tornando-se assim homocedástica a partir desse ponto.

O gráfico abaixo mostra como se deu o ajustamento dos dados no modelo.

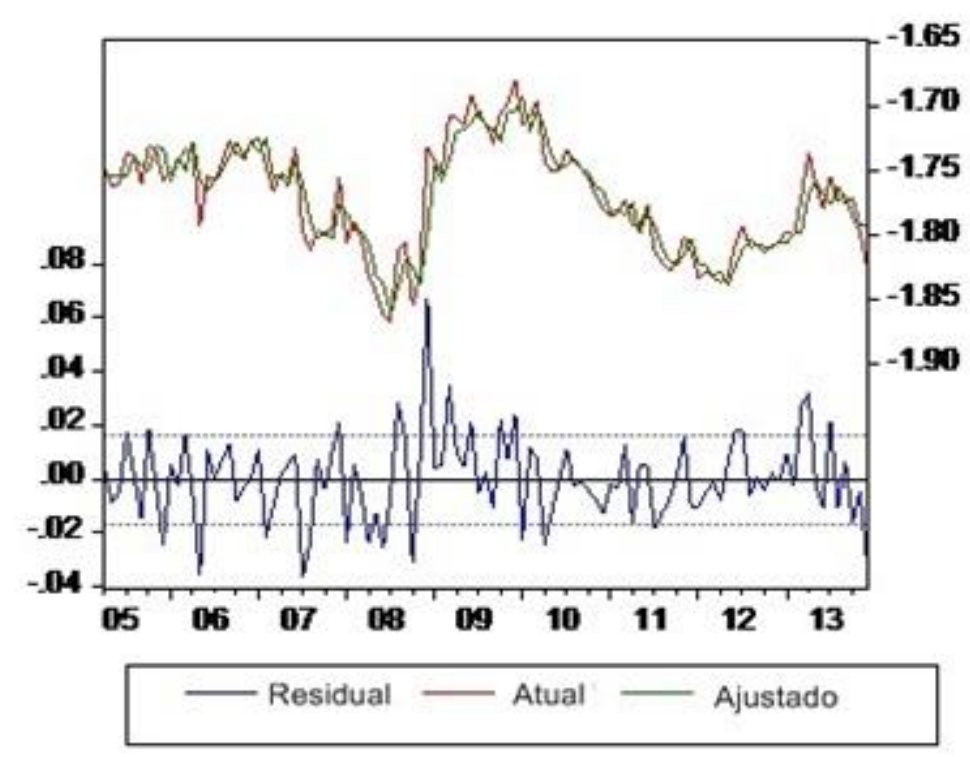

Gráfico 1 - Ajustamento dos dados

Fonte: Resultados do modelo

As variáveis independentes estão explicando o ajuste do modelo em aproximadamente $85,57 \%$ (R-quadrado=0,855767).

O Teste de Durbin-Watson retornou a seguinte estatística $\mathrm{DW}=1,886336$, sendo assim não rejeitamos a hipótese nula e, portanto podemos afirmar com $95 \%$ de confiança que não existe autocorrelação, assim sendo os resíduos são independentes.

A Tabela abaixo apresenta as estatísticas descritivas da regressão, assim como o Teste de Durbin-Watson, e os critérios de informação Akaike e Schwarz (quanto menor o CIA e o CIS, melhor o modelo).

Tabela 2 - Estatísticas descritivas e Teste de Durbin-Watson

\begin{tabular}{cc|cc}
\hline R-quadrado & 0,855767 & Média da variável dependente & $-1,770767$ \\
R-quadrado ajustado & 0,845358 & Desvio padrão (var. depend.) & 0,041944 \\
Erro padrão da regressão & 0,016494 & Critério de informações Akaike & $-5,315704$ \\
Soma do quadrado dos resíduos & 0,026390 & Critério Schwarz & $-5,113497$ \\
Log da probabilidade & 287,0745 & Estatística-F & 82,21748 \\
Estatísticas Durbin-Watson & 1,886336 & Prob. (estatística-F) & 0,000000 \\
\hline
\end{tabular}

Fonte: Resultados do modelo 
O Teste de Dickey-Fuller aumentado, sem consideração de defasagens retornou a seguinte estatística-t: $\mathrm{t}=-9,524596$, os valores críticos do teste são, ao nível de $1 \%$ de significância $=-3,494378$, ao nível de $5 \%$ de significância $=-2,889474$ e ao nível de $10 \%$ de significância $=-2,581741$, assim rejeitamos a hipótese nula, e concluímos que não existe raiz unitária na serie. $\mathrm{O}$ mesmo teste foi realizado com duas defasagens e com dez defasagens e retornaram as seguintes estatísticas-t $=-10,33279,-7,149009$ respectivamente, sendo os valores críticos do teste próximos aos especificados anteriormente também rejeitamos a hipótese nula, e concluímos que não existe raiz unitária na serie. Podemos concluir a partir dos resultados que se trata de uma série estacionária. A tabela abaixo mostra os resultados do teste:

Tabela 3 - Teste de Dickey-Fuller aumentado para verificação de raiz unitária

\begin{tabular}{ccccc}
\hline & & 0 Defasagens & 2 Defasagens & 10 Defasagens \\
& Estatistica-t & $-9,524596$ & $-10,33279$ & $-7,149009$ \\
& Prob. & 0,00000 & 0,00000 & 0,00000 \\
\hline Valores críticos do teste & Nivel 1\% & $-3,494378$ & $-3,496346$ & $-3,503049$ \\
& Nivel 5\% & $-2,889474$ & $-2,890327$ & $-2,89323$ \\
& Nivel 10\% & $-2,581741$ & $-2,582196$ & $-2,58374$ \\
\hline
\end{tabular}

Fonte: Resultados do modelo

\section{Conclusão}

A decisão sobre o endividamento depende de vários fatores como taxa de juros, prazos e necessidade de liquidez imediata. Sendo o ambiente econômico no Brasil favorável a contratação de dívidas, as famílias brasileiras tenderão a se endividar. Com o crescente índice de endividamento surge então a questão sobre o quanto esse aumento no índice da divida das famílias poderia afetar a estabilidade econômica do país.

Tendo sido observada uma recente crise e o aumento das preocupações com a criação ou melhoramento de meios que tentam mitigar seus efeitos, tornou-se relevante a análise de um desses meios (o índice de Basiléia), visto que ocorreram reformas no Acordo de Basiléia, impondo regras mais rígidas sobre o capital mínimo regulatório.

Foi então realizada a análise das relações entre o índice de Basiléia, que visa aumentar a liquidez bancaria, e o índice de endividamento familiar (que mostra os riscos a que uma instituição financeira se encontra exposta, visto que podem ocorrer inadimplências, o que realizaria um risco de liquidez).

Os dados mostram que durante o período analisado houve considerável aumento no índice de endividamento das famílias brasileiras. Dado os resultados do modelo, podemos comparar o sistema financeiro brasileiro ao mercado americano, visto, por exemplo, da ótica dos autores que apontam o começo da crise financeira de 2008, como consequência do alto endividamento das famílias americanas no ramo de hipotecas, o que gerou inadimplementos em massa fazendo com que os bancos sofressem com a falta de liquidez e desestabilizando todo o sistema financeiro (as reservas de capital não foram capazes de mitigar os efeitos da inadimplência).

Além disso, um nível de endividamento elevado provoca diminuição no consumo, o que provocará mudanças econômicas como na inflação e nas taxas de juros de mercado. 
O índice mínimo de capital (índice de Basiléia) visa funcionar como uma espécie de "amortecedor", para que os eventos de inadimplência em determinado setor financeiro não se propaguem vindo a desencadear uma nova crise em todo sistema financeiro.

\section{Referências}

ABBA, G. O.; PETER, Z.; INYANG, E. E. Capital Adequacy Ratio and Banking Risks in the Nigeria Money Deposit Banks. Research Journal of Finance and Accounting, v. 4, n. 17, p. 17-25, 2013.

ABUSHARBA, M. T.; TRIYUWONO, I.; ISMAIL, M.; RAHMAN, A. F. Determinants of Capital Adequacy Ratio (CAR) in Indonesian Islamic Commercial Banks. Global Review of Accounting and Finance, v. 4, n. 1, 2013.

ALENCAR, L. S. Um exame sobre como os bancos ajustam seu índice de Basiléia no Brasil. Trabalhos para discussão, Banco Central do Brasil, agosto 2011.

ALMEIDA, K. C. O desafio da administração do risco de crédito no século XXI e seu reflexo na economia brasileira. Pensamento \& Realidade. Revista do Programa de Estudos PósGraduados em Administração-FEA, v. 17, 2005.

ALMEIDA, M. S.; BERTUCCI, L. A.; SOUZA, J. R. Influência da crise financeira mundial, na estrutura econômica das instituições financeiras bancárias brasileiras e seus reflexos no índice de Basiléia: uma abordagem comparativa. Revista de contabilidade e organizações, vol.6 n¹6, 2012, p.73-94.

BATENI, L.; VAKILIFARD, H.; ASGHARI, F. The Influential Factors on Capital Adequacy Ratio in Iranian Banks. International Journal of Economics and Finance, v. 6, n. 11, p. p108, 2014.

BERTUCCI, L. A.; AMARAL, H. F.; SOUZA, F. H. R. de. O impacto do acordo da Basiléia sobre Instituições Financeiras Brasileiras. Revista de Administração de Empresas, v. 44, n. SPE, p. 74-82, 2004.

BIS. Bank for International Settlements. Basel III: The Liquidity Coverage Ratio and liquidity risk monitoring tools, 2013. Disponível em: < http://www.bis.org/publ/bcbs238.htm $>$. Acesso em 8 de out. de 2014.

BOKHARI, I. H.; ALI, S. M.; SULTAN, K. Determinants of Capital Adequacy Ratio in Banking Sector: An Empirical Analysis from Pakistan. Academy of Contemporary Research Journal, 2012.

BOLLERSLEV, T. Generalized autoregressive conditional heteroskedasticity. Journal of Econometrics, vol. 31, p. $307-327,1986$.

BRITO, G. A. S.; ASSAF NETO, A. Modelo de classificação de risco de crédito de empresas. Revista Contabilidade \& Finanças, v. 19, n. 46, p. 18-29, 2008. 
BROWN, M.; HAUGHWOUT, A.; LEE, D.; KLAAUW, W. V. D. The financial crisis at the kitchen table: trends in household debt and credit. Current Issues in Economics and Finance, v. 19, n. 2, 2013.

Caderno de Educação Financeira Gestão de Finanças pessoais, Banco Central do Brasil $2013 . \quad$ Disponível em: <http://www.bcb.gov.br/pre/pef/port/caderno_cidadania_financeira.pdf $>$. Acesso em 6 de out. de 2014.

CAJU, P. D.; ROELANDT, T.; NIEUWENHUYZE, C. V.; ZACHARY, M. D. Household debt: evolution and distribution. Economic Review, 2014.

CAPELLETTO, L. R.; CORRAR, L. J. Índices de risco sistêmico para o setor bancário. Revista de Contabilidade Financeira, v. 19, n. 47, p. 6-18, 2008.

CERRI, R. N.; BRITTO, P. A. Risco de crédito e spread bancário em carteiras de financiamentos com recursos do BNDES . Revista de Economia e Administração, v. 13, n. 2, p. 214-234, 2014.

COSTA, S.; FARINHA, L. O endividamento das famílias: uma análise microeconómica com base nos resultados do inquérito à situação financeira das famílias. Relatório de Estabilidade Financeira maio, Lisboa, p. 137-163, 2012.

CUNHA, A. C.; LUCAS, H. F. De Basiléia para "Brasiléia": trazendo o Acordo Internacional de Capital para a realidade brasileira. IV Encontro Internacional da Associação Keynesiana Brasileira- Área 1- Economia Internacional e Finanças (2011).

DIAMOND, D. W.; DYBVIG, P. H. Bank runs, deposit insurance, and liquidity. The journal of political economy, p. 401-419, 1983.

ENGLE, R. F. Autoregressive conditional heteroskedasticity with estimates of variance of United Kingdom inflation. Econometrica, vol.50, n. 4, p. 987 - 1007, 1982.

ERLINGSSON, E. J.; TEGLIO, A.; CINCOTTI, S. STEFANSSON, H., STURLUSON, J. T.; RABERTO, M. Housing market bubbles and business cycles in an agent-based credit economy. Economics, v. 8, n. 8, p. 1, 2014.

GONÇALVES, R. M. L.; BORGES, C. R.; MOREIRA, N. P.; ,MENEZES, R. S. S.; MATOS, D. A. Livre Admissão e Risco de Crédito em uma Cooperativa do Alto Paranaíba. RACE-Revista de Administraçâo, Contabilidade e Economia, v. 13, n. 1, 2014.

GOTTSCHALK, R., SODRÉ, M. C. O novo acordo da Basiléia no Brasil: impactos sobre bancos públicos e privados. Revista Economia e Política Internacional, análise estratégica n8 jan/jun 2006.

GUJARATI, D. N.; PORTER, D. C. Econometria Básica-5. McGraw Hill Brasil, 2011.

KEESE, M. Who feels constrained by high debt burdens? Subjective vs. objective measures of household debt. Journal of Economic Psychology, v. 33, n. 1, p. 125-141, 2012. 
Manual da Supervisão. Banco Central do Brasil 2009. Disponível em: < https://www3.bcb.gov.br/gmn/visualizacao/listarDocumentosManualPublico.do?method=visu alizarDocumentoInicial\&itemManualId=205\&idManual=1> . Acesso em 6 de out. de 2014.

MARTINS, O. S.; PEREIRA, C. C.; CAPELlETTO, L. R.; PAUlO, E. Capacidade Informativa Das Demonstrações Financeiras Dos Bancos Brasileiros: Uma Análise Sob a Ótica Do Risco De Liquidez (Informational Capacity of the Financial Statements of Brazilian Banks: An Analysis from the Perspective of Liquidity Risk). Sociedade, Contabilidade e Gestão, v. 7, n. 2, 2012.

MILEO, R.; KIMURA, H.; KAYO, E. K. Análise do Modelo CreditRisk+ em uma amostra de portfólio de crédito. Contextus, v. 11, n. 1, 2013.

MORETTIN, P. A.; TOLOI, C. M. C. Análise de séries temporais. 2a ed. São Paulo: Egard Blucher, 2006.

PAULA, L. F. Financiamento, crescimento econômico e funcionalidade do sistema financeiro: uma abordagem pós-keynesiana. Estudos Econômicos (São Paulo), v. 43, n. 2, p. 363-396, 2013.

PINTO, N. G. M.; CORONEL, D. A. Abordagem do Endividamento, Superendividamento e Inadimplência nas Capitais Brasileiras (2010-2012). Revista de Administração da UEG, v. 4, n. 2, p. 73, 2013.

Relatório de economia bancária e crédito, Banco Central do Brasil 2012 (rebc_2012) Disponível em: < http://www.bcb.gov.br/pec/depep/spread/rebc_2012.pdf>. Acesso em 1 de set. de 2014.

Risco de Credito , Disponivel em: $<$ http://www.bcb.gov.br/glossario.asp?Definicao=594\&idioma=P\&idpai=GLOSSARIO $>$ Aces so em 27 de fev. de 2015.

Risco de Liquidez, Disponivel em <http://www.bcb.gov.br/glossario.asp?Definicao=751\&idioma=P\&idpai=GLOSSARIO> Acesso em 01 de mar. De 2015.

RUBERTO, I. V. G.; VIEIRA, K. M. V.; FILHO, R. B.; SILVEIRA, V. G. A Influência dos Fatores Macroeconômicos sobre o Endividamento das Famílias Brasileiras no período 20052012. Estudos do CEPE, Santa Cruz do Sul, n. 37, p. 58-77, jan./jun. 2013.

SANTOS, J. A. C. Bank capital regulation in contemporary banking theory: A review of the literature. Financial Markets, Institutions \& Instruments, v. 10, n. 2, p. 41-84, 2001.

SBÂRCEA, I. R. International Concerns for Evaluating and Preventing The Bank Risks Basel I Versus Basel II Versus Basel III. 21st International Economic Conference 2014, IECS 2014, 16-17 May 2014, Sibiu, Romania.

SILVA, E. N.; JÚNIOR, P.; SILVA, S. da. Sistema financeiro e crescimento econômico: uma aplicação de regressão quantílica. Economia Aplicada, v. 10, n. 3, p. 425-442, 2006. 
VIEIRA, A. L. B. D.; ROMA, C. M. S.; FERREIRA, B. P.. O Custo do Crédito Pessoal em Relação ao Nível de Endividamento das Famílias Brasileiras e à Taxa de Juros Selic. Revista Economia \& Gestão, v. 14, n. 36, p. 138-160, 2014.

YANAKA, G. M.; HOLLAND, M. Basiléia II e exigência de capital para risco de crédito dos bancos no Brasil. Revista Brasileira de Finanças 2010, vol.8 pp.167-195.

YURDAKUL, F. Macroeconomic modelling of credit risk for banks. Procedia-Social and Behavioral Sciences, v. 109, p. 784-793, 2014.

50 Maiores bancos e o consolidado do Sistema Financeiro Nacional. Disponível em: < http://www4.bcb.gov.br/top50/port/esc_met_v1.asp> Acesso em 12 jan. 2015. 